\title{
Autism Spectrum Disorders Among Pre-primary and Primary School Pupils in Uyo, Nigeria
}

\author{
Paulinus Umoren Essien ${ }^{1}$, Mkpouto Udeme Akpan ${ }^{1, ~ *, ~ E m m a n u e l ~ E y o ~ E k a n e m ² ~}$ \\ ${ }^{1}$ Department of Paediatrics, University of Uyo Teaching Hospital, Uyo, Nigeria \\ ${ }^{2}$ Department of Paediatrics, University of Calabar Teaching Hospital, Calabar, Nigeria
}

Email address:

ecleck@yahoo.com (P. U. Essien), mkpoutoakpan@yahoo.com (M. U. Akpan), profekanem@gmail.com (E. E. Ekanem)

*Corresponding author

\section{To cite this article:}

Paulinus Umoren Essien, Mkpouto Udeme Akpan, Emmanuel Eyo Ekanem. Autism Spectrum Disorders Among Pre-primary and Primary School Pupils in Uyo, Nigeria. American Journal of Psychiatry and Neuroscience. Vol. 5, No. 6, 2017, pp. 60-65. doi: 10.11648/j.ajpn.20170506.11

Received: August 24, 2017; Accepted: September 21, 2017; Published: November 8, 2017

\begin{abstract}
Autism Spectrum Disorders are a group of neuro-developmental disorders prevalent in school children. There is no known study on its prevalence among children in mainstream primary schools in our environment. The aim of this study was to determine the prevalence and pattern of autism spectrum disorders among children in Uyo, Nigeria. A cross-sectional study was conducted among 2,641 pupils aged 3-11 years from twelve primary schools in Uyo. The Gilliam Autism Rating Scale-second edition (GARS-2) and Gilliam Asperger's Disorder Scale (GADS) were completed by both the class teachers and the parents. Student ' $t$ ' test was used to compare means and chi square to compare proportion. $p$-value $<0.05$ was considered significant. Twenty- nine had Autism Spectrum Disorders (ASD) giving a prevalence rate of $1.1 \%$. Nineteen had pervasive developmental disorder, not otherwise specified (PDD-NOS), 8 had autistic disorder (AD) and 2 had Asperger's disorder (AsD). ASD was commoner in males, young age group (3-5 years) and children of upper social class. It was concluded that ASD is prevalent among children in mainstream primary schools in Uyo, Nigeria. Appropriate healthcare policy should be put in place to cater for the special needs of these children.
\end{abstract}

Keywords: Autism Spectrum Disorders, Pupils, Uyo

\section{Introduction}

Autism Spectrum Disorders are a group of neurodevelopmental disorders prevalent in school children [1]. The disorders are characterized by qualitative variations and severity differences in the development of reciprocal social or emotional interaction, non-verbal communicative behaviours such as eye contact and facial expression, peer relationship, initiating and sustaining conversation, delayed or lack of expressed language and social imaginative play, with the presence of restricted repetitive and stereotyped pattern of behaviour, interest and activities [1], [2]. The spectrum ranges from the most severe, Autistic Disorder (AD) to the less severe forms; Asperger's Disorder (AsD) and Pervasive Developmental Disorder, Not Otherwise Specified (PDD-NOS) [1].

Autism spectrum disorders have been accorded prominent attention in America, Europe and Asia [3], [4], [5]. On the contrary, the African continent, Nigeria inclusive has a dearth of data on autism spectrum disorders due to lack of epidemiological studies [6], [7], [8]. Prevalence of autism spectrum disorders vary from one geographical location to the other depending largely on study methodology [2], [3], [4], [7]. A prevalence rate of $2 \%$ was reported in United States of America while prevalence rate of $1.57 \%$ and $2.62 \%$ were reported in United Kingdom and South Korea respectively [5], [6], [7], [8], [9].

Most studies on prevalence of autism spectrum disorders in Africa, Nigeria inclusive were carried out in children with mental impairment, a restricted population of children not in regular schools [8], [10], [11]. These studies might not be a true reflection of the prevalence of autism spectrum disorders in the general population.

Schools in Western countries are required by law to identify all pupils with disabilities, including those with 
autism spectrum disorders at start of school so as to place them on appropriate interventions [9], [12], [13]. This is lacking in Nigeria. Since early detection of this condition with prompt and appropriate intervention can improve the outcome, this screening for autism spectrum disorders in school pupils in Nigeria was imperative.

\section{Materials and Method}

Uyo is the capital of Akwa-Ibom State, one of the six states in the South-South political zone of Nigeria. A total of 2,641 pupils aged 3-11 years chosen from twelve schools were studied over a seven month period (November 2014 to May 2015). These were pupils who had spent at least two weeks in that particular class [14], [15] and whose parents had given consent for their inclusion in the study.

Written permission to conduct the study was obtained from the Akwa-Ibom State Ministry of Education. Ethical approval was obtained from the Institutional Health Research Ethical committee of the University of Uyo Teaching Hospital. Informed verbal/written consent was also obtained from the parents of the study subjects.

Uyo urban has 55 primary schools with a population of 71,659 pupils. Twelve schools were randomly selected using table of random numbers and this was $21 \%$ of the target population. The twelve schools selected had a total population of 14,240 pupils out of which 12,135 met the inclusion criteria. The twelve schools comprised of seven private primary schools and five government schools. The number of pupils selected from each of the twelve schools was determined proportionately based on the total number of pupils that met the inclusion criteria from that school.

\subsection{Assessment for Autistic Disorder}

The Gilliam Autism Rating Scale, second edition (GARS2) which is a standardized instrument was used to assess the pupils for autistic disorder [15]. The GARS-2 is a frequency based instrument that rates the subscale items according to the frequency of occurrence. It has three subscales with 14 items each derived from a given domain based on the definition of AD adopted by DSM-IV-TR and American Society of Autism. On the right side of the scale, against each of the 14 items, are four specified types of rating scored 0-3 depending on the frequency of occurrence of the behavior assessed. A rate of 0 denotes 'Never Observed' which means that the teacher has never seen the pupil behaved in the manner stated in the item considered. A score of 1 is for 'Seldom Observed' meaning that the pupil behaves in the manner as stated in the item once or two times in a six hour period. A score of 2 means the behavior assessed is observed at a frequency of 3 to 4 times per 6 hours; and a frequency of 5 or 6 times or more is scored 3. The assessment was completed by the class teachers. On completion of the rating, the scores were summed up for each of the subscale and this was regarded as the raw scores. The raw scores for each subscale was used to derive the corresponding standard score and percentile rank using the conversion table. Standard scores for the subscales were added and converted into autism index and percentile ranking using another conversion table. The parent interview section of GARS-2 was administered on parents of all pupils who had autism index score of 70 and above. The parent interview was scored in the 'yes' or 'no' format. A 'no' response connotes a delay or abnormal functioning during the first three years of life.

A subject was adjudged to have autistic disorder if the following were met:

1. An autistic index score of 85 and above

2. Total subscale standard score of 21 and above

3. Percentile rank of 16 and above

4. Development in the first three years of life showing delay and/or abnormal functioning in socialization, communication and/or imaginative or symbolic play

5. Answers to the 'keyquestions' support assessment for autistic disorder.

Pupils who had autistic index score of between 70-84, total subscale standard score of 12-18, percentile ranking of 2-5 and developmental delay and/or abnormal functioning in the first three years or later age in the three domains were further subjected to evaluation to rule out asperger's disorder using the Gilliam Asperger's Disorder Scale (GADS) [15], [16]. Children with autistic index of $<70$, total subscale score of 9 and less and percentile rank of 1 were regarded as unlikely to have autism spectrum disorder [15].

\subsection{Assessment for Asperger's Disorder}

Gilliam asperger's disorder scale, a standardizes normreferenced instrument was used to assess the pupils who had the GARS-2 autism index score of 70-84 for asperger's disorder. [15], [16] The instrument has a section that records the child's demographic information and the 'Response Form' section which consists of four subscales:- social interaction, restricted pattern of behaviour, cognitive pattern and pragmatic skill subscales. The social interaction subscale has 10 items, numbered 1-10; restricted pattern of behavior has eight, numbered 11-18; while cognitive pattern of behavior and pragmatic skill subscales have 7 items each numbered 19-25 and 26-32 respectively. The GADS' parent interview questionnaire is administered in 'yes' or 'no' format and it provides a series of questions for parents, caregivers or guardians who have adequate knowledge of the individual that is assessed. The items on the subscales were scored according to frequency of occurrence ranging from 0 3. A score of 0 was given when the behavior was 'never observed', 1 when 'seldom observed', 2 and 3 when 'sometimes observed' and 'frequently observed' respectively. The assessment was completed by the class teachers. On completion of the rating, the sum of the scores for each subscale gave the raw score for the subscale. The raw score for each subscale was used to derive the corresponding standard score and percentile rank using the conversion table. The total sum of the standard scores of the four subscales was converted into the Asperger's Disorder Quotient (ADQ) and its percentile rank using a conversion table. The parent interview section of the GADS was filled by the parents. 
A child was adjudged to have Asperger's disorder when the following conditions are met:-

1. GARS-2 autistic index between 70 and 84

2. GADS' ADQ score of 80 and above [16]

3. Percentile rank of 9 to 100

4. No significant delay or abnormality involving language, cognition, age-appropriate help skills, adaptive behavior and curiosity about environment

5. The skill questions supported the assessment of such a child for Asperger's disorder

\subsection{Assessment for PDD-NOS}

For any of the children assessed using GARS-2 or GADS to be adjudged as having PDD-NOS, the following must be met:

1. Must have met the criteria 1-3 for AD but had delay and/or abnormal functioning in socialization, communication and/or imaginative or symbolic play domain beyond three years of age OR

2. Those with impairment in one or two of the three subscales of GARS-2 but had autistic index score of 70 and above, with delay and/or abnormal functioning involving any or all of the three developmental domains, and at the same time did not meet the criteria for AD based on GARS-2 or AsD based on GADS.

\subsection{Determination of Social Class}

Parents were asked to state their occupation and educational attainment. Social classification was done using the scheme proposed by oyedeji [17]. Subjects were classified into five grades (I-V) based on their parental occupational and educational levels. Grade I represents the highest social class, comprises of children whose parents are senior public servant, professionals, large scale businessmen and contractors, with university education or its equivalent. Grade II comprises of children of intermediate civil servants and senior school teachers with secondary education and some further training; grade III junior school teachers, drivers and artisans with secondary education, grade IV petty traders, labourers and messengers or other related workers with primary education and grade $\mathrm{V}$ (the lowest class ) the unemployed, students, full time housewives and subsistence farmers with no formal education. Subjects were further grouped into upper (IandII), middle (III) and lower (IV, V) social classes.

Statistical analysis was performed using SPSS version 17. Frequencies and percentages were calculated for categorical data. Student ' $t$ ' test was used for comparison of means and chi square for comparison of proportion. p-value $<0.05$ was considered significant.

\section{Results}

Of the 2,641 pupils studied, 1,368 (51.8\%) were from private primary schools while $1,273(48.2 \%)$ were from public primary schools. Majority of the pupils belonged to the age range of 6-11 years with a median age of 8 years 2 months. A significantly greater number of young pupils attended private schools while the older pupils were found in the public schools $(\mathrm{p}<0.01)$. There was no significant difference in the proportion of male and female pupils in the study $(p=0.47)$. More children from the upper social class attended private schools while more of the children in public schools were from the lower social class. Table 1 shows some demographic characteristics of the pupils according to type of school.

Table 1. Compares the Demographic Characteristics of Private and Public School Pupils.

\begin{tabular}{|c|c|c|c|c|c|c|}
\hline \multirow[t]{2}{*}{ Demographic characteristics } & & \multirow{2}{*}{$\begin{array}{l}\text { School } \\
\text { Private N(\%) }\end{array}$} & \multicolumn{4}{|l|}{ type } \\
\hline & & & Public N(\%) & Total N(\%) & Chi square & p-value \\
\hline \multicolumn{7}{|l|}{ Age group } \\
\hline & $3-5$ years & $439(32.1)$ & 151(11.9) & $590(22.3)$ & 155.53 & 0.01 \\
\hline & $6-11$ years & $929(67.9)$ & $1122(88.1)$ & 2051(77.7) & & \\
\hline \multicolumn{7}{|l|}{ Gender } \\
\hline & Male & $748(54.7)$ & $678(53.3)$ & $1426(54.0)$ & 0.53 & 0.47 \\
\hline & Female & $620(45.3)$ & $595(46.7)$ & $1215(46.0)$ & & \\
\hline \multicolumn{7}{|l|}{ Social class } \\
\hline & Upper & $1249(91.3)$ & $3(0.2)$ & $1252(47.4)$ & 2269.72 & 0.01 \\
\hline & Middle & $99(7.2)$ & $240(18.9)$ & $339(12.8)$ & & \\
\hline & Lower & $20(1.5)$ & $1030(80.9)$ & $1050(39.8)$ & & \\
\hline
\end{tabular}

A total of twenty-nine pupils had autism spectrum disorders with a prevalence rate of $1.1 \%$. Of these, two $(6.9 \%)$ had features that met the criteria for Asperger's disorder, eight (27.6\%) had autistic disorder while 19 (65.5\%) had PDD-NOS.

Table 2 compares some demographic characteristics of autistic and non autistic children. Among pupils with ASD, those in the age group 3-5 years were more in number while greater number of non autistic pupils belonged to the age range of $6-11$ years $(p<0.01)$. Sixteen $(55.2 \%)$ out of the 29 autistic pupils were aged 3 - 5 years while $13(44.8 \%)$ belonged to the $6-11$ years age group. Conversely, $78 \%$ of the non autistic pupils were aged 6- 11 years while $22 \%$ were 3 - 5 years old. More males had autistic disorder than females, with the male to female ratio of 3.8:1. Among the non autistic pupils, 1,403 (53.7\%) were males while 1,209 $(46.3 \%)$ were females giving a ratio of $1.2: 1$. Majority (75$9 \%$ ) of the autistic pupils attended private schools while $24.1 \%$ attended public schools $(\mathrm{p}=0.01)$. Prevalence of ASD was highest in the upper social class $(69 \%)$; followed by the 
pupils from the lower social class $(17.2 \%)$ while the middle class constituted the least number $(13.8 \%)$. Among the non autistics, 47.2) were from the upper class, $40 \%$ from the lower social class while $12.8 \%$ from the middle social class.

Table 2. Compares the Demographic Characteristics of Autistic and Non Autistic Children.

\begin{tabular}{|c|c|c|c|c|c|c|}
\hline Demographic characteristics & & Non autistic children $N(\%)$ & Autistic children N(\%) & Chi square & df & p-value \\
\hline \multicolumn{7}{|l|}{ Age } \\
\hline & $3-5$ years & $574(22.0)$ & $16(55.2)$ & 18.22 & 1 & 0.01 \\
\hline & $6-11$ years & $2038(78.0)$ & $13(44.8)$ & & & \\
\hline \multicolumn{7}{|l|}{ Gender } \\
\hline & Male & $1403(53.7)$ & $23(79.3)$ & 7.57 & 1 & 0.01 \\
\hline & Female & $1209(46-3)$ & $6(20.7)$ & & & \\
\hline \multicolumn{7}{|l|}{ Schooltype } \\
\hline & Public & $1266(48.5)$ & $9(31.0)$ & & & \\
\hline \multicolumn{7}{|l|}{ Socialclass } \\
\hline & Upper & $1232(47.2)$ & $20(69.0)$ & 6.64 & 2 & 0.04 \\
\hline & Middle & $335(12.8)$ & $4(13.8)$ & & & \\
\hline & Lower & $1045(40.0)$ & $5(17.2)$ & & & \\
\hline
\end{tabular}

The mean GARS-2 scores of the three subscales of stereotype behaviours, communication and social interaction were greater for the autistic pupils than for non autistic pupils. The differences were statistically significant $(\mathrm{p}<0.01)$. The mean GARS-2 standard score for stereotyped behaviours was 7.66 (SD1.56) for autistic pupils and 1.08 (SD0-54) for non autistic pupils $(95 \% \mathrm{CI}=6.36-6.78, \mathrm{t}=62.56, \mathrm{p}<0.01)$. The mean GARS-2 standard score for communication was 8.66 (SD2.51) in autistic pupils and 1.06 (SD0.29) for non autistic pupils $(95 \% \mathrm{CI}=7.41-7.78, \mathrm{t}=80.12, \mathrm{p}<0.01)$. The mean
GARS-2 standard score for socialization was 7.10 (SD2.11) for autistic children while 1.03 (SD0.29) for non autistic pupils $(95 \% \mathrm{CI}=5.94-6.20, \mathrm{t}=90.47, \mathrm{p}<0.01)$. The mean for the sums of the standard scores of the three subscales of the GARS-2 for autistic pupils (23.41) was greater than that for non autistic pupils (3.18). This was statistically significant with $\mathrm{p}<0.01$. The mean autism index of the GARS-2 for the autistic children (86.34) was above the cut-off for assessment for ASD and below in non autistic children (41.42). These are illustrated in table 3 .

Table 3. Compares the GARS-2 Scores of Autistic Pupils and Non Autistic Pupils.

\begin{tabular}{|c|c|c|c|c|c|c|}
\hline GARS-2 parameter & Type of pupil & Mean of GARS-2 score & Standard deviation & t-distribution & $95 \%$ CI & p-value \\
\hline \multicolumn{7}{|l|}{ Sster } \\
\hline & Autistic & 7.66 & 1.56 & 62.56 & $6.36-6.78$ & $<0.01$ \\
\hline & Non autistic & 1.08 & 0.54 & & & \\
\hline \multicolumn{7}{|l|}{ Scomm } \\
\hline & Autistic & 8.66 & 2.51 & 80.12 & $7.41-7.78$ & $<0.01$ \\
\hline & Non autistic & 1.06 & 0.44 & & & \\
\hline \multicolumn{7}{|l|}{ Ssocial } \\
\hline & Autistic & 7.10 & 2.11 & 90.47 & $5.94-6.20$ & $<0.01$ \\
\hline & Non autistic & 1.03 & 0.29 & & & \\
\hline \multicolumn{7}{|l|}{ SumSS } \\
\hline & Autistic & 23.41 & 3.81 & 91.48 & $19.80-20.67$ & $<0.01$ \\
\hline & Non autistic & 3.18 & 1.12 & & & \\
\hline \multicolumn{7}{|l|}{ Autindex } \\
\hline & Autistic & 86.34 & 7.04 & 87.98 & $43.92-45.93$ & $<0.01$ \\
\hline & Non autistic & 41.42 & 2.65 & & & \\
\hline
\end{tabular}

Sster $=$ standard score for stereotype behaviours

Scomm $=$ standard score for communication

Ssocial $=$ standard score for social interaction

SumSS $=$ sum of standard scores

Autindex $=$ autism index

\section{Discussion}

This study is about the only study in Nigeria on primary school pupils, including pre-primary school pupils with ASD in mainstream school. It was not surprising that the private schools had significantly more pupils belonging to the younger age group of $3-5$ years than the public schools. Privately owned primary schools have better capacity and experience to retain pre- primary school children than government primary schools. This is because pre- primary school education was barely practiced in public schools until about two decades ago when the Federal Government of Nigeria introduced the Early Childhood Care Development 
and Education [18]. This scheme absorbs children between 3 and 5 years old.

The finding that higher population of older pupils were found in public schools is in consistent with report by Urwick [19] which demonstrated that the mean ages of pupils in the various primary grade levels were higher in public school pupils than those in private schools.

Though male pupils were greater in number than females in both private and public schools in this study, the gender difference was marginal and compares well with previous study on school children in that environment [20].

There was a concentration of children from the upper social class in private schools and this had been reported by previous authors [20]. This could be explained by the fact that families with financial prowess to shoulder the cost prefer sending their wards to private schools which are perceived to have a better quality of education compared to public schools [21]. The high proportion of pupils from lower social class in public primary schools could probably be due to the free education programme implemented by the government in public schools in the study environment.

The prevalence rate of ASD of $1.1 \%$ in this study compares well with 1.0\% reported by Barron-Cohen et al [9] among mainstream primary school pupils in a region of the United Kingdom but higher than $0.63 \%$ reported in the same country among children with developmental and behavioural problems [22]. The disparity in the prevalence could be due to the sampling method. The method used by Cohen et al was questionnaire-based and relied on reports from parents and teachers while the other study made use of relevant health professionals to ascertain the cases [22]. A higher prevalence of $2.64 \%$ was obtained from South Korea in a population study that recruited subjects from both mainstream primary schools and the special education registry for primary school aged children [5].

The pattern of prevalence of the three subtypes of ASD in this study supports the frequency of ASD subtypes earlier reported in other parts of the world [3], [5], [22]. The finding that $\mathrm{AD}$ constituted $27.6 \%$ of the total autistic pupils with AsD and PDD-NOS constituting $72.4 \%$ is similar to what was observed by Kim et al [5] among pupils in regular primary schools in South Korea.

The finding that higher number of children in the age bracket $3-5$ years had ASD was also reported by Bertrand et al [12]. Male preponderance in this study supports the observation obtained in earlier studies on ASD [3], [5], [8], [12]. The male/female ratio for children with ASD of 3.8:1 compares well with 4:1 reported by both Bakare et al [8] and Izuwah et al [23] among children in a therapeutic centre in South-eastern Nigeria and special education centre in Port Harcourt respectively.

The study finding that children with ASD were more prevalent among the private primary school pupils could be explained by the fact that parents perceive private primary schools in Nigeria to have better educational quality, including superior rphysical facilities or environment to cater for vulnerable children like pupils with ASD [21].
The social class distribution of the pupils with ASD in this study assumed the pattern observed among the whole population study. A similar observation was made by Ritvo et al in Utah, United States of America [24]. Though social class has been shown not to influence the occurrence of ASD, [25], [26] this study demonstrated a higher number of autistic pupils belonging to the upper social class. This observation is in keeping with findings from other studies on ASD among African children [10], [27]. These studies were on children with mental retardation whose parents probably had a better financial capability to back up action-oriented attitude to orthodox care than parents of autistic children from lower social class. The upper class preponderance could also be due to the skew caused by the greater number of pupils from the upper social class in private schools and the perceived high drop-out rate of autistic pupils in public primary schools.

The standard scores for the three subscales as well as the autism index based on GARS-2 were significantly higher among the autistic pupils than the non autistic pupils. These findings support the fact that GARS-2 has a good discriminative ability for ASD [28], [29].

\section{Conclusion}

Our findings suggest that children with ASD are present in mainstream primary schools in Uyo, Nigeria; with PDD-NOS being the most prevalent and AsD the least. This calls for appropriate healthcare policy to cater for the special needs of pupils with Autism Spectrum Disorder in Nigeria.

\section{Acknowledgements}

The authors acknowledge the Government of Akwa Ibom State for granting us written permission to carry out the study. We are also grateful to the head teachers and teachers of selected schools. The parents of the subjects are equally acknowledged.

\section{References}

[1] American Psychiatric Association. Diagnostic and Statistical Manual of Mental Disorders. $4^{\text {th }}$ Edition, Text Revision. Washington D C: APA 2000.

[2] World Health Organization. International Classification of Diseases: Diagnostic Criteria for Research, $10^{\text {th }} \mathrm{Ed}$. Geneva, WHO 1993.

[3] Fombonne E. Epidemiology of pervasive developmental disorders. Pediatr Res 2009; 65 (6): 591-8.

[4] Biumberg SJ, Bramlett MD, Kogan MD, Scieve LA, Jones JR et al. Changes in prevalence of parent-reported autism spectrum disorders in school aged U. S. Children: 2007 to 2010-2011. CDC: Nat Health Statistics Report 2013; 65: 1-12.

[5] Kim FS, Leventhal BL, Koh J, Fombonne E, Laska E et al. Prevalence of autism spectrum disorders in a total population sample. Am J Psychiatry 2011; 168(9): 904-12. 
[6] Bakare MO, Munir KM. Autism spectrum disorders in Africa. In: A comprehensive book on autism spectrum disorders. Muhammad-Reza M. (Ed); In Tech, Croatia 2011; 183-94.

[7] Bakare MO, Munir KM. Autism spectrum disorders (ASD) in Africa: a perspective. Afr J Psychiatry 2011; 14 (3): 208-10.

[8] Bakare MO, Ebigbo PO, Ubochi VN. Prevalence of autism spectrum disorders among Nigerian children with intellectual disabilities: a stop gap assessment. J HealthCare Poor Underserved 2012; 23 (2): 513 - 8.

[9] Baron-Cohen S, Scott FJ, Allison C, Williams J, Bolton P et al. Prevalence of autism spectrum conditions: UK schoolbased population study. Br J Psychitry 2009; 194 (6): 500-9.

[10] Eldin AS, Habib D, Noufal A, Farrag S, Bazaid K et al. Use of M-CHAT for a multi-national screening of young children with autism in the Arab countries. Int Rev Psychiatry 2008; 20 (3): 281-9.

[11] Lotter V. Childhood autism in Africa. J Child Psychol Psychiatry 1978; 19 (3): 231-44.

[12] Bertrand J, Mars A, Boyle C, Bove F. Prevalence of autism in a United States population: The Brick township, New Jersey, Investigation. Pediatr 2001; 108 (5): 1155-61.

[13] Individuals with Disabilities Education Act (IDEA) of 2004, 34 CFS 300.101

[14] Schopler E, Bourgondien MEV, Love SR, Wellman GJ. Childhood autism rating scale-second edition. London: Pearson 2010.

[15] Gilliam JE. Gilliam Autism RatingScale, Second Edition, Examiner's Manual. Austin, Tx: PRO-ED 2006.

[16] Gilliam JE. GADS; Gilliam Asperger disorder scale, Examiner's manual. Austin, TX :PRO-ED 2003.

[17] Oyedeji G. Socio-economic and cultural background of hospitalized children in Ilesha. Nig J Paediatr 1985; 12 (4): 111-7.

[18] Ejieh MUC. Pre-primary education in Nigeria: policy implementation and problems. Elem Edu Online 2006; 5 (1): 58-64.
[19] Urwick J. Determinants of the private costs of primary and early childhood education: findings from Plateau State, Nigeria. Internat J Edu Dev 2992; 22 (2): 131-44.

[20] Akpan MU, Ojinnaka NC, Ekanem EE. Behavioural problems among school children in Nigeria. SAJP 2010; 16 (2): 50-5.

[21] Onuka AOU, Arowojolu AF. An evaluation of parents' patronage of private primary schools in Abeokuta, Nigeria. Internat J Afri Am Studies 2008; 7 (2): 58-70.

[22] Chakrabarti S, Faombonne E. Pervasive developmental disorders in preschool children. JAMA 2001; 285 (24): 3093 9.

[23] Izuwah DN, Alikor EAD. Autism in Port Harcourt: social impairment at presentation. Nig J Paediatr 2011; 38 (1): 32

[24] Wing L, Yeates SR, Brierly LM, Gould J. The prevalence of early childhood autism: comparison of administrative and epidemiologic studies. Psychol Med 1976; 6 (1): 89-100.

[25] Volkmar FR, Klin A. Issues in classification of autism and other related conditions. In: Volkmar FR, Paul R, Klin A, Cohen D (Eds). Handbook of autism and pervasive developmental disorders $\left(3^{\text {rd }} \mathrm{Ed}\right)$. John Wiley and Sons Inc, New Jersey 2005; 5-41.

[26] Mankoski RE, Collins M, Ndosi NK, Mgalla EH, Sarwatta VV, Folstein SE. Etiologies of autism in a case-series from Tanzania. J Autism Dev Disord 2006; 36 (8): 1039-51.

[27] Baird G, Simonoff E, Pickles A, Chandler S, Loucas T et al. Prevalence of disorders of autism spectrum in a population cohort of children in South Thames: The special needs and autism project (SNAP). Lancet 2006; 368 (9531): 210-5.

[28] Capone G, Grados M, Kaufmann W, Bernard-Ripoll S, Jewell A. Down syndrome and co-morbid autism spectrum disorders: Characterization using the aberrant behavior checklist. Am J Med Genet A 2005; 134 (4): 373-80.

[29] Goldstein S, Naglieri JA. Autism spectrum rating scales (ASRS): Product overview. Multi-Health Syst Inc 2010. 